\title{
Post-traumatic vision-threatening orbital haematoma managed with needle aspiration
}

\author{
Rachna Meel, Amogh Kittur, Deepsekhar Das
}

Dr RP Centre for Ophthalmic Sciences, All India Institute of Medical Sciences, New Delhi, Delhi, India

\section{Correspondence to Dr Deepsekhar Das; doc.deep.das@gmail.com}

Accepted 1 May 2020

\section{DESCRIPTION}

A 14-year-old male patient presented to eye casualty of a tertiary care centre in northern India with a history of rapidly outward protrusion of the left eye (LE) following a blunt trauma to the same side 10 days ago (figure 1). The patient was playing cricket with his friends when he was hit with a ball on his face. There was no history of loss of consciousness, vomiting or bleeding from nose and ear.

On examination, visual acuity was $20 / 20$ in the right eye (RE) and finger counting with accurate projection of rays in the LE. There was a severe restriction in the extraocular motility of the LE, the globe was proptosed and Hertel's exophthalmometry readings were $15 \mathrm{~mm}$ in the right eye and $21 \mathrm{~mm}$ in the left eye at Base of 102. There was an inferior dystopia of $5 \mathrm{~mm}$. The left upper eyelid was swollen, chemosed and there was lagophthalmos of $3 \mathrm{~mm}$. The conjunctival surface of the LE was hyperaemic, and the cornea was hazy and oedematous with evidence of exposure keratopathy. The anterior chamber was deep with no evidence of hyphema, iridodialysis or cataract. There were choroidal folds on fundus examination. The RE was within normal limits. Ultrasonography B scan of the orbit revealed a superior orbital subperiosteal collection of fluid (video 1). Contrast-enhanced CT (CECT) scan of the head and orbit revealed superior orbital haematoma (figure 2). A $23 \mathrm{G}$ needle was passed at the superior sulcus in between the globe and orbital rim and $12 \mathrm{~mL}$ of haematoma was drained (video 2). There was an immediate decrease in LE proptosis and the correction of lagophthalmos (figure 3). The patient was started on topical moxifloxacin eyedrops and carboxymethyl cellulose. There was a remarkable improvement in 3 days and the vision recovered to 20/40 (figure 4).

A traumatic subperiosteal haematoma occurs more commonly in the younger age group. ${ }^{1}$ It is almost

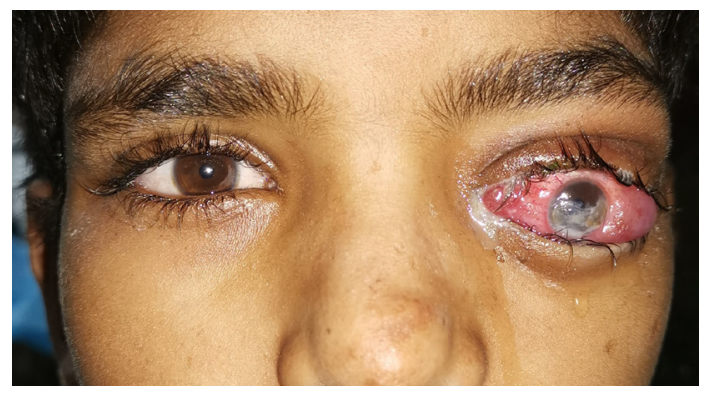

Figure 1 Clinical photograph of patient at presentation showing proptosis of the left eye, conjunctival chemosis and corneal exposure keratopathy.

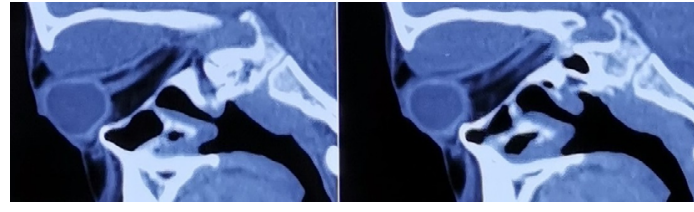

Figure 2 Contrast-enhanced CT sagittal scan revealing haematoma in the superior subperiosteal space.

always located in the superior orbit. A subperiosteal haematoma occurs due to the rupture of subperiosteal vessels or as an extension of subgaleal haematomas. Clinical features depend on the amount of blood collected and the location of the haematoma. Orbital subperiosteal haematoma involving the superior orbit typically presents with proptosis and hypoglobus. Vision is affected either due to optic nerve compression in the orbit or because of corneal involvement as a consequence of lagophthalmos and exposure keratopathy. At times, there can also be severe pain due to corneal nerve stimulation. The patient may also report diplopia due to extraocular muscle movement restriction. $^{2}$

CECT scan of the head and orbit is the preferred initial investigation to determine the presence of any haematoma and its size. It also aids in picking up

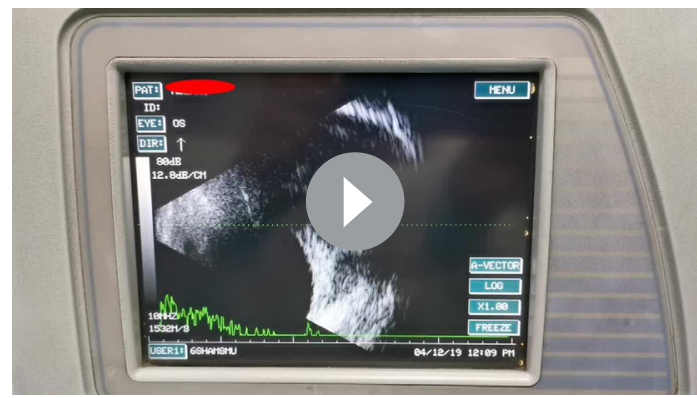

Video 1 Ultrasonography B scan of the left eye orbit showing the collection of fluid in the subperiosteal space.

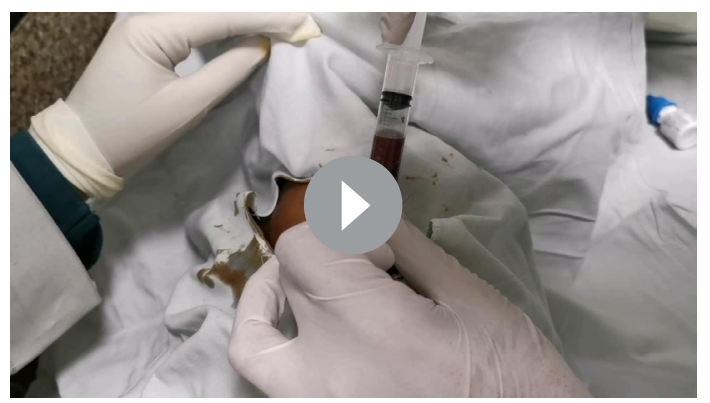

Video 2 Surgical procedure of aspiration of haematoma. 


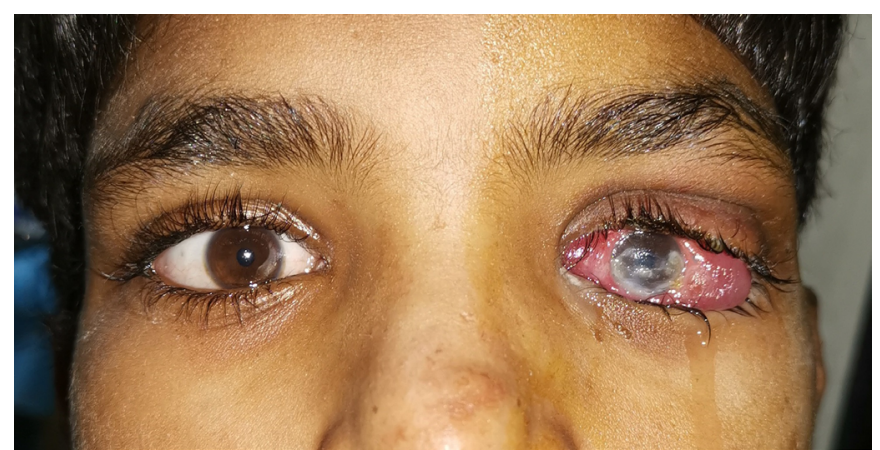

Figure 3 Clinical photograph of the patient immediately after aspiration of haematoma, showing a remarkable decrease in proptosis.

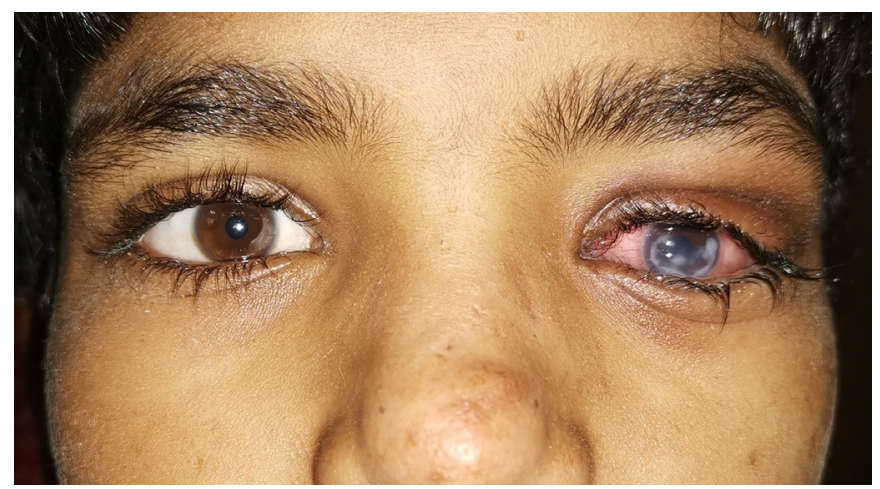

Figure 4 Clinical photograph of the patient 4 days after aspiration, showing healing keratopathy.

associated orbital wall fractures. Typical signs in a CT scan may include a well-defined, high-attenuation lesion with a broad base abutting the orbital roof, inferiorly displaced orbital content and a stretched optic nerve. ${ }^{3}$

As an adjunctive investigation, MRI can also be used. MRI in a typical case of subperiosteal will reveal a biconvex, sharply demarcated lesion of varied signal intensity. In the hyperacute stage, T1-weighted images may show a relatively low signal (fresh blood), whereas in the subacute stage, a high signal (3-7 days, before lysis of red blood cells). However, in T2-weighted images, a high signal will be seen in the hyperacute stage and a low signal in the subacute stage. $^{4}$

Management options of post-traumatic subperiosteal haematoma include observation, needle aspiration and surgical evacuation. Gillum and Anderson first reported the reversal of complete vision loss, following orbital decompression in a case of

\section{Patient's perspective}

I thought my son is going to lose his vision after 4 days of the trauma as the situation was progressing very badly. Luckily, we reached All India Institute of Medical Sciences and the needle aspiration was performed.

\section{Learning points}

- Post-traumatic orbital subperiosteal haematoma can lead to permanent visual loss and requires immediate intervention.

- An immediate drainage of the haematoma can potentially nullify the risk of vision loss in this situation.

subperiosteal haematoma. ${ }^{5}$ A conservative approach with observation and intravenous pulse steroids is usually employed in cases without visual impairment at the time of presentation. Although needle aspiration is performed in all vision-threatening and early cases. Surgical exploration with drainage is to be performed, if it is vision threatening with a dry tap on needle aspiration. ${ }^{6}$

Contributors RM and DD: took part in diagnosing the case. AK and DD: took part in the management of the case; responsible in making the manuscript for submission.

Funding The authors have not declared a specific grant for this research from any funding agency in the public, commercial or not-for-profit sectors.

Competing interests None declared.

Patient consent for publication Parental/guardian consent obtained.

Provenance and peer review Not commissioned; externally peer reviewed.

\section{ORCID iD}

Deepsekhar Das http://orcid.org/0000-0002-4446-0274

\section{REFERENCES}

1 Woo KI, Kim YD. Subperiosteal hematoma of the orbit associated with sinusitis. Korean J Ophthalmol 1997:11:118-22.

2 Wolter JR. Subperiosteal hematomas of the orbit in young males: a serious complication of trauma or surgery in the eye region. Trans Am Ophthalmol Soc 1979;77:104-20.

3 Seigel RS, Williams AG, Hutchison JW, et al. Subperiosteal hematomas of the orbit: angiographic and computed tomographic diagnosis. Radiology 1982;143:711-4.

4 Atalla ML, McNab AA, Sullivan TJ, et al. Nontraumatic subperiosteal orbital hemorrhage. Ophthalmology 2001;108:183-9.

5 Gillum WN, Anderson RL. Visual loss in subperiosteal hemReversibleatoma of the orbit. Ophthalmic Surg 1981;12:203-9.

6 Kim U, Arora V, Shah A, et al. Clinical features and management of posttraumatic subperiosteal hematoma of the orbit. Indian J Ophthalmol 2011;59:55-8.

Copyright 2020 BMJ Publishing Group. All rights reserved. For permission to reuse any of this content visit

https://www.bmj.com/company/products-services/rights-and-licensing/permissions/

BMJ Case Report Fellows may re-use this article for personal use and teaching without any further permission.

Become a Fellow of BMJ Case Reports today and you can:

- Submit as many cases as you like

- Enjoy fast sympathetic peer review and rapid publication of accepted articles

- Access all the published articles

Re-use any of the published material for personal use and teaching without further permission

Customer Service

If you have any further queries about your subscription, please contact our customer services team on +44 (0) 2071111105 or via email at support@bmj.com.

Visit casereports.bmj.com for more articles like this and to become a Fellow 